\title{
Mapping oral health related quality of life to generic health state
} values

\author{
David S Brennan* and A John Spencer
}

Address: Australian Research Centre for Population Oral Health, School of Dentistry, Faculty of Health Sciences, The University of Adelaide, South Australia

Email: David S Brennan* - david.brennan@adelaide.edu.au; A John Spencer - john.spencer@adelaide.edu.au

* Corresponding author

Published: 07 August 2006

BMC Health Services Research 2006, 6:96 doi:10.1 186/1472-6963-6-96

This article is available from: http://www.biomedcentral.com/1472-6963/6/96

(C) 2006 Brennan and Spencer; licensee BioMed Central Ltd.

This is an Open Access article distributed under the terms of the Creative Commons Attribution License (http://creativecommons.org/licenses/by/2.0), which permits unrestricted use, distribution, and reproduction in any medium, provided the original work is properly cited.
Received: 05 May 2006

Accepted: 07 August 2006

\begin{abstract}
Background: A summary utility index is useful for deriving quality-adjusted life years (QALY) for cost analyses or disability weights for burden of disease studies. However, many quality of life instruments provide descriptive profiles rather than a single utility index. Transforming quality of life instruments to a utility index could extend the use of quality of life instruments to costs analyses and burden of disease studies. The aims of the study were to map a specific oral health measure, the Oral Health Impact Profile to a generic health state measure, the EuroQol, in order to enable the estimation of health state values based on OHIP data.
\end{abstract}

Methods: Data were collected from patients treated by a random sample of South Australian dentists in 200 I-02 using mailed self-complete questionnaires. Dentists recorded the diagnosis of dental conditions and provided patients with self-complete questionnaires to record the nature, severity and duration of symptoms using the EuroQol (EQ-5D) and 14-item version of the Oral Health Impact Profile (OHIP- I4) instruments. Data were available from 375 patients (response rate $=72 \%$ ). A random two-thirds sample of patients was used in tobit regressions of EQ-5D health state values estimated using OHIP-I4 in a model with categories of OHIP responses as indicator variables and in a model with OHIP responses as continuous variables. Age and sex were included as covariates in both models. The remaining one-third sample of patients was used to test the models.

Results: The OHIP item 'painful aching in mouth' was significantly related to health state values in both models while 'life less satisfying' was also significant in the continuous model. Mean forecast errors relative to the mean observed health state value were higher when fitted to the categorical model $(17.4 \%)$ compared to the continuous model $(I 5.2 \%)(P<0.05)$.

Conclusion: The findings enable health state values to be derived from OHIP-I4 scores for populations where utility has not or cannot be measured directly.

\section{Background}

Oral health related quality of life measures have been developed because objective clinical measures of disease provided little insight into the impact of oral disorders on daily living and quality of life [1]. The value of oral health related quality of life measures in the description of the 
experience of disease and treatment could be enhanced further through the development of a summary utility index that could measure health state values on a scale from zero to one where zero represents worst health and one best health [2]. Transforming health related quality of life instruments to a summary utility index is useful for deriving quality-adjusted life years (QALY) for cost analyses [3], or disability weights for burden of disease studies [4].

The Oral Health Impact Profile (OHIP) is a disease-specific measure of people's perceptions of the social impact of oral disorders on their well-being [5]. OHIP contains 49 questions that capture seven conceptually formulated dimensions based on Locker's theoretical model of oral health [6], and the OHIP-14 was developed as a shorter version of the OHIP for settings where the full battery is inappropriate [7]. While the OHIP is widely used as a measure of oral health related quality of life it does not provide an index of health state value.

The EuroQol was developed as a standardised generic (non-disease-specific) instrument for describing and valuing health-related quality of life [8]. The EuroQol is intended to complement other forms of quality of life measures and it was purposefully developed to generate a generic index of health that places health states on scale from zero (worst health) to one (best health). The EuroQol is widely used internationally and reported to have adequate construct and convergent validity, but is highly skewed and has relatively poor sensitivity especially in relation to disease-based outcomes research [9].

The EuroQol is an index measure that provides a single number that represents an individuals' health status and preference value for that health state [10]. The EuroQol has been used in population surveys such as in the U.K. to establish population norms for the instrument [11], and has been linked to the development of disability weights that have application in burden of disease studies based on disability-adjusted life years [12]. Disability-adjusted life years were developed in conjunction with the World Bank and have been used for priority setting in health policy [13], for example, by the World Health Organization [14]. In Australia the Australian Burden of Disease and Injury Study used the EuroQol to estimate disability weights for a range of disease categories for which there were no published weights [15].

The aims of the study were to map a specific oral health measure, the Oral Health Impact Profile to a generic health state measure, the EuroQol, in order to enable the estimation of health state values based on OHIP data.

\section{Methods \\ Ethical review}

The research project was reviewed and approved by the Human Research Ethics Committee of the University of Adelaide.

\section{Design}

The Burden of Oral Disease Study was conducted as a cross-sectional study using a mailed survey approach. Dentists were provided with a practitioner logbook in the dentist questionnaire to record for the first 1 to 5 consecutive adult patients (depending on study group assignment of dentist) of a random clinical day the diagnosis of the oral disease or condition treated and treatment they performed. At the conclusion of treatment each practitioner (except those in the study group that had no patient questionnaires to distribute) passed on a survey kit to their sampled patient(s) containing a patient questionnaire, cover letter and explanation sheet. Sampled patients completing the patient questionnaire recorded basic socio-demographic characteristics and data concerning the nature, severity and duration of their symptoms. The primary rationale for this 2-stage sampling methodology was to allow linkage of dentist-assessed oral health status to patient perceptions of quality of life. The patient questionnaires were identified using the practitioner identification number allowing linkage between the practitioner logbook data and patient questionnaire data, but maintaining the anonymity of each patient to the investigators.

\section{Instrument development}

A pilot study was conducted which collected five patients per dentist in order to establish the feasibility of the 2stage methodology. Since the optimum number of patients to sample from dentists was not known, dentists in the main study were randomised into six equal-sized groups in order to assess the sample size-related efficiency and response properties of recording data on from 1 to 5 patients and distributing between 0 to 5 patient questionnaires.

\section{Sampling and data collection}

A 2-stage sampling design was used where stage 1 involved sampling dentists and stage 2 involved sampling of patients within selected dentists. Dentists were randomly sampled from the South Australian Dental Register. The Dental Register was used as a sampling frame as it provides a comprehensive listing of all persons registered to work as dentists in the State of South Australia, and is therefore representative of the target population of dentists. Sampled dentists were randomised into one of seven equal-sized study groups to assess the optimum number of patients to sample from dentists and sent a mailed selfcomplete dentist questionnaire along with up to five self- 
complete patient questionnaires depending on the study group. Note that dentists in the group that had no patient questionnaires to distribute recorded details of 5 patients in their dentist questionnaire, while dentists in all other groups recorded the same number of patients in their dentist questionnaire as they distributed patient questionnaires.

Data were collected during 2001-02 with a primary approach letter sent initially to each dentist, followed a week later by the survey materials, with a reminder card two weeks later, and up to four follow-up mailings of survey materials to dentists who had not yet responded in order to ensure higher response rates [16].

The emphasis of the project was to obtain precise estimates of the component measures of the burden of oral disease. These are typically expressed as percentages, such as the percentage of persons or percentage of time experiencing symptoms of a given degree of severity. Taking a parameter size of $10 \%$ as a reference estimate for any given measure, in order to achieve a level of precision of $20 \%$ or less relative standard error, a minimum target sample of $n=225$ patients was required. This would provide an acceptable level of precision for estimates as low as $10 \%$ in size, and better precision for any estimates larger than $10 \%$ in size.

\section{Data items}

Dentists recorded the details of the dental conditions that patients had, and patients recorded their experience of those dental conditions. In the patient questionnaire, patients were asked if the dental conditions had caused problems in each of six health state dimensions using the European Quality of Life indicator or EuroQol (EQ-5D+) instrument [8]. The six health state dimensions were: mobility (e.g, walking about), self-care (e.g, washing, dressing), usual activities (e.g., work, study, housework, family or leisure), pain/discomfort, anxiety/depression and cognition (e.g, memory, concentration, coherence, IQ). The EuroQol measures each of these six dimensions according to a 3-level response grading from $1=$ no problems, 2 = some/moderate problems and 3 = extreme problems. Patients were also asked to rate their experience of dental problems in the last year using the OHIP-14 [7], which uses 14 items to capture measures of the seven dimensions of functional limitation, physical pain, psychological discomfort, physical disability, psychological disability, social disability and handicap. For each of the 14 OHIP questions subjects were asked how frequently they had experienced impact in the preceding 12 months using a Likert-type response scale re-coded as a Guttman scale 4 = very often, 3 = fairly often, $2=$ occasionally, $1=$ hardly ever and $0=$ never.

\section{Measures}

The main output measure was calculated by converting EuroQol item responses to health state values, where each set of responses on the standard 5-item instrument was matched to a health state value where $0=$ death and $1.0=$ perfect health by an algorithm derived from modelling values [17] using health state preferences elicited from a general population [8]. The responses to the OHIP-14 instrument were coded into categories of 'Never', 'Hardly ever' and 'Occasionally/Fairly often/Very often' with each category converted into indicator variables with values of one if there was a response in that category or with values of zero if there was no response in that category. Age was entered in years and sex was coded as one for males and zero for females.

\section{Data analysis}

The characteristics of responding patients were compared descriptively with published data on dental patients and the Australian population. A random sample of two thirds of the respondents was used to construct models of health state values (see Figure 1 for an outline of the sampling and analysis). Two tobit regression models were constructed using the EQ-5D based health state value as the dependent variable with the independent variables of OHIP-14 items, sex and age. Tobit regression was used to account for censoring of the characteristically bounded nature of health state values that can result in biased and inconsistent estimates using ordinary least-squares regression [18-20]. One model used the OHIP-14 items as categorical variables with the category 'Never' as the reference category, while the other model used the OHIP-14 item responses as continuous variables that were coded from 0 to 4 . Cases with missing data on the dependent or independent variables were excluded from the analysis. Nonsignificant terms were retained for comparability across models, and their potential value in controlling for confounding [21]. The remaining one third sample of the respondents was used to test the models by comparing fitted versus actual values using forecast errors. Forecast errors were calculated by subtracting fitted values from actual health state values and dividing by the mean actual health state value to convert absolute forecast errors into relative forecast errors as a percentage of the actual sample mean health state value. Model building strategies also included testing model fit after inclusion of additional terms such as age-squared to model non-constant age effects and interactions between OHIP-14 items, and examining correlations of independent variables for possible collinearity. The design effect of clustering of patients within sampled dentists was calculated and used as a weight to adjust the reported confidence intervals. 
Stage 1: Dentists sampled

Stage 2: Patients sampled

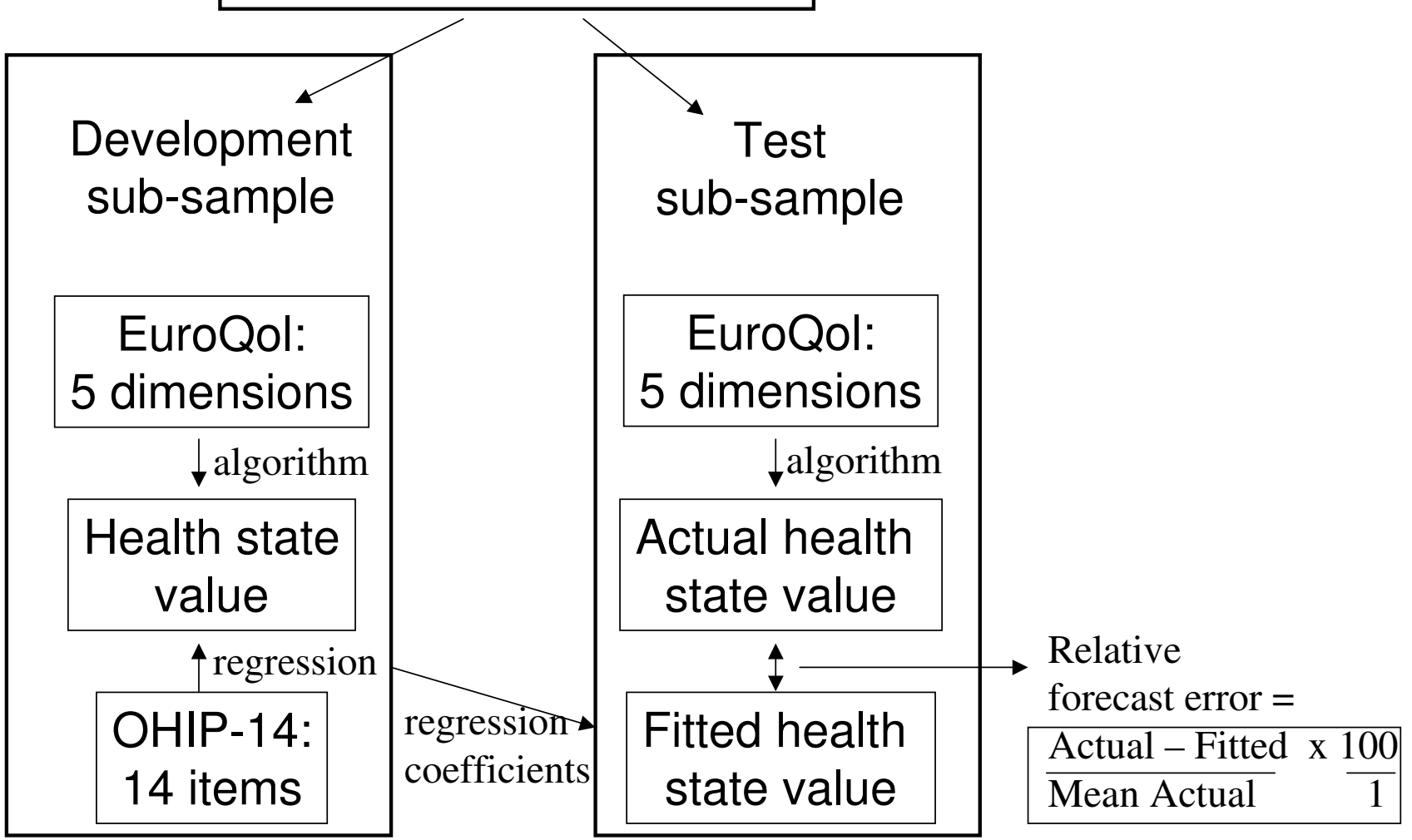

Figure I

Outline of sampling and analysis.

\section{Results}

\section{Response}

A total of 378 dentists responded to the survey (response rate $=60 \%$ ). Response rates between study groups varied from 49 to $70 \%$ and tended to be higher in study groups that required dentists to sample less patients, but the effect was not monotonic (Table 1). Data were available for 375 patients from the patient questionnaire, comprising a response rate of $72 \%$ of patients sampled, with response rates between study groups varying from 69 to $92 \%$.

\section{Characteristics of patients}

The characteristics of patients are presented in Table 2 where data from private general practice [22] and Australian population estimates $[23,24]$ are presented for comparison. The majority of patients were female (59.5\%), born in Australia (75.5\%), had dental insurance (64.8\%) and had visited a dentist in the last 12 months (65.3\%). The main reason for dental visiting was for other dental problems not involving relief of pain (46.7\%), followed by check-ups $(35.2 \%)$ and emergency visits involving relief of pain $(18.1 \%)$.

\section{Distribution of variables}

The mean health state value was 0.852 (95\% confidence interval 0.840 to 0.964 ). Table 3 shows that a minority of patients reported symptoms in the 'Occasionally/Fairly often/Very often' category, ranging from $3.6 \%$ for 'unable to function' to $46.0 \%$ for 'uncomfortable eating'. Responses in the 'hardly ever' category ranged from $6.9 \%$ for 'unable to function' to $29.0 \%$ for 'painful aching in the mouth'. Mean values for the OHIP-14 items ranged from 0.140 for 'unable to function' up to 1.355 for 'uncomfortable eating'. 
Table I: Response to the dentist and patient questionnaires

\begin{tabular}{|c|c|c|c|c|c|c|c|c|}
\hline & \multirow[b]{3}{*}{$\begin{array}{l}\text { Patients sampled } \\
\text { per dentist }\end{array}$} & \multicolumn{4}{|c|}{ Dentist questionnaire } & \multicolumn{3}{|c|}{ Patient questionnaire } \\
\hline & & \multirow[b]{2}{*}{$\begin{array}{l}\text { Number of dentists } \\
\text { responding }\end{array}$} & \multirow[b]{2}{*}{$\begin{array}{l}\text { Response } \\
\text { rate (\%) }\end{array}$} & \multicolumn{2}{|c|}{ Patients recorded } & \multicolumn{2}{|c|}{ Patients recorded } & \multirow[b]{2}{*}{$\begin{array}{c}\text { Response } \\
\text { rate (\%) }\end{array}$} \\
\hline & & & & Number & Percent & Number & Percent & \\
\hline Pilot study & 5 & 60 & $(65)$ & 135 & $(17.9)$ & 93 & $(24.8)$ & (69) \\
\hline Main study (a) & 0 & 61 & (70) & 237 & $(31.4)$ & - & $(-)$ & $(-)$ \\
\hline Main study (b) & 1 & 56 & (62) & 37 & $(4.9)$ & 29 & (7.7) & (78) \\
\hline Main study (c) & 2 & 54 & $(60)$ & 49 & (6.5) & 45 & $(12.0)$ & (92) \\
\hline Main study (d) & 3 & 43 & (49) & 61 & (8.1) & 41 & $(10.9)$ & (67) \\
\hline Main study (e) & 4 & 50 & (58) & 118 & (I5.6) & 84 & $(22.4)$ & (7I) \\
\hline Main study (f) & 5 & 54 & (57) & 119 & $(15.7)$ & 83 & $(22.1)$ & (70) \\
\hline Total & & 378 & (60) & 756 & $(100.0)$ & 375 & $(100.0)$ & (72) \\
\hline
\end{tabular}

\section{Regression models}

The OHIP-14 items and sociodemographic covariates had relatively high pseudo R-squared values (Table 4). OHIP items relating to 'painful aching in mouth' were significantly related to health state values in both models while 'life less satisfying' was also significant in the continuous model. In each case, the regression coefficients were negative indicating that responses to the OHIP-14 items were associated with lower health state values.

Table 5 shows the mean forecast errors for both the categorical and continuous variable models. Mean forecast errors relative to the mean observed health state value were higher when fitted to the categorical model $(17.4 \%)$ compared to the continuous model $(15.2 \%),(\mathrm{P}<0.05)$. However, the forecast errors were not consistently higher for the categorical model at each level of observed health state value.

Table 6 demonstrates the relationship between observed and fitted values within selected ranges of observed health state values using the categorical model. At each level of observed health state values the fitted values slightly overestimated the observed health state value.

Note that alternative versions of the models were attempted using an age-squared term and also exploring interactions between OHIP items, but as they did not substantially alter pseudo R-squared values or forecast errors, the results for these additional models are not presented. Examination of correlations among the independent variables indicated that OHIP items were positively corre-

Table 2: Characteristics of patients compared with private general practice and Australian population estimates

\begin{tabular}{|c|c|c|c|}
\hline & $\begin{array}{l}\text { Burden of Oral Disease Study } \\
\qquad(n=375)\end{array}$ & $\begin{array}{l}\text { Private general practice }{ }^{(a)} \\
(n=4,858)\end{array}$ & $\begin{array}{c}\text { Australian population } \\
(n=7,829)\end{array}$ \\
\hline & $\%[95 \% \mathrm{Cl}]$ & $\%$ & $\%$ \\
\hline \multicolumn{4}{|l|}{ Sex } \\
\hline$\%$ Female & $59.5[54.3-64.7]$ & 54.9 & (b) 50.4 \\
\hline \multicolumn{4}{|l|}{ Place of birth } \\
\hline$\%$ Australian & $75.5[70.9-80.1]$ & n.a. & (b) 76.4 \\
\hline \multicolumn{4}{|l|}{ Dental insurance status } \\
\hline$\%$ Insured & $64.8[59.7-69.9]$ & 47.8 & (c) 34.8 \\
\hline \multicolumn{4}{|l|}{ Reason for dental visit } \\
\hline Check-up & $35.2[30.1-40.3]$ & 41.1 & (c) 45.1 \\
\hline Emergency & $18.1[16.0-20.2]$ & 28.6 & n.a. \\
\hline Other dental problem & $46.7[4 \mid .4-52.0]$ & 30.8 & n.a. \\
\hline \multicolumn{4}{|c|}{ Time since last dental visit } \\
\hline$\%$ visited in last 12 months & $65.3[60.2-70.4]$ & n.a. & (c) 61.3 \\
\hline
\end{tabular}

(a): Longitudinal Study of Dentists' Practice Activity 1998-99

(b): Australian Bureau of Statistics 2002

(c): National Dental Telephone Interview Survey 1999

n.a.: denotes data not available 
Table 3: Descriptive statistics for OHIP-I4 items as categorical and continuous variables

\begin{tabular}{|c|c|c|c|c|c|}
\hline \multirow[b]{2}{*}{ Variable } & \multirow[b]{2}{*}{$\mathbf{n}$} & \multirow[b]{2}{*}{ Percent } & \multirow[b]{2}{*}{ Mean } & \multicolumn{2}{|c|}{$95 \% \mathrm{Cl}$} \\
\hline & & & & Lower bound & Upper bound \\
\hline Trouble pronouncing words & 365 & & 0.296 & 0.223 & 0.369 \\
\hline Never & & 81.6 & & & \\
\hline Hardly ever & & 10.1 & & & \\
\hline Occas., F/Often, V/Often & & 8.2 & & & \\
\hline Sense of taste worsened & 356 & & 0.399 & 0.315 & 0.483 \\
\hline Never & & 76.1 & & & \\
\hline Hardly ever & & 11.5 & & & \\
\hline Occas., F/Often, V/Often & & 12.4 & & & \\
\hline Painful aching in mouth & 359 & & 1.100 & 0.990 & 1.211 \\
\hline Never & & 36.5 & & & \\
\hline Hardly ever & & 29.0 & & & \\
\hline Occas., F/Often, V/Often & & 34.5 & & & \\
\hline Uncomfortable eating & 361 & & 1.355 & 1.230 & 1.479 \\
\hline Never & & 32.4 & & & \\
\hline Hardly ever & & 21.6 & & & \\
\hline Occas., F/Often, V/Often & & 46.0 & & & \\
\hline Felt self-conscious & 361 & & 1.094 & 0.961 & 1.227 \\
\hline Never & & 48.8 & & & \\
\hline Hardly ever & & 15.0 & & & \\
\hline Occas., F/Often, V/Often & & 36.3 & & & \\
\hline Felt tense & 362 & & 0.820 & 0.705 & 0.936 \\
\hline Never & & 57.2 & & & \\
\hline Hardly ever & & 16.3 & & & \\
\hline Occas., F/Often, V/Often & & 26.5 & & & \\
\hline Diet unsatisfactory & 359 & & 0.457 & 0.365 & 0.549 \\
\hline Never & & 73.8 & & & \\
\hline Hardly ever & & 12.5 & & & \\
\hline Occas., F/Often, V/Often & & 13.7 & & & \\
\hline Interrupt meals & 363 & & 0.548 & 0.460 & 0.636 \\
\hline Never & & 64.2 & & & \\
\hline Hardly ever & & 20.7 & & & \\
\hline Occas., F/Often, V/Often & & 15.2 & & & \\
\hline Difficulty relaxing & 362 & & 0.597 & 0.499 & 0.695 \\
\hline Never & & 64.9 & & & \\
\hline Hardly ever & & 16.9 & & & \\
\hline Occas., F/Often, V/Often & & 18.2 & & & \\
\hline Been embarrassed & 365 & & 0.800 & 0.686 & 0.914 \\
\hline Never & & 57.0 & & & \\
\hline Hardly ever & & 18.6 & & & \\
\hline Occas., F/Often, V/Often & & 24.4 & & & \\
\hline Irritable with other people & 364 & & 0.525 & 0.436 & 0.613 \\
\hline Never & & 66.5 & & & \\
\hline Hardly ever & & 18.7 & & & \\
\hline Occas., F/Often, V/Often & & 14.8 & & & \\
\hline Difficulty doing usual jobs & 365 & & 0.282 & 0.216 & 0.348 \\
\hline Never & & 80.3 & & & \\
\hline Hardly ever & & 12.6 & & & \\
\hline Occas., F/Often, V/Often & & 7.1 & & & \\
\hline Life less satisfying & 363 & & 0.562 & 0.464 & 0.660 \\
\hline Never & & 68.6 & & & \\
\hline Hardly ever & & 13.2 & & & \\
\hline Occas., F/Often, V/Often & & 18.2 & & & \\
\hline Unable to function & 363 & & 0.140 & 0.095 & 0.186 \\
\hline Never & & 89.5 & & & \\
\hline Hardly ever & & 6.9 & & & \\
\hline Occas., F/Often, V/Often & & 3.6 & & & \\
\hline
\end{tabular}

Note: "Occas., F/Often, V/Often" refers to "Occasionally, Fairly often, Very often" 
Table 4: Regression models of Health state values by OHIP-I4

\begin{tabular}{|c|c|c|c|c|c|c|}
\hline \multirow[b]{2}{*}{ Variable } & \multicolumn{3}{|c|}{ Categorical model( $(\mathrm{l})(\mathrm{n}=209)$} & \multicolumn{3}{|c|}{ Item model $(n=209)$} \\
\hline & Coef. & S.E. & $\mathbf{P}$ & Coef. & S.E. & $\mathbf{P}$ \\
\hline Trouble pronouncing words & & & & 0.0154 & $(.025)$ & 0.544 \\
\hline Hardly ever & 0.0826 & $(.054)$ & 0.128 & & & \\
\hline Occas., F/Often, V/Often & 0.0750 & $(.072)$ & 0.296 & & & \\
\hline Sense of taste worsened & & & & 0.0020 & $(.022)$ & 0.930 \\
\hline Hardly ever & -0.3670 & $(.062)$ & 0.557 & & & \\
\hline Occas., F/Often, V/Often & -0.0238 & $(.056)$ & 0.674 & & & \\
\hline Painful aching in mouth & & & & -0.0905 & $(.020)$ & 0.000 \\
\hline Hardly ever & -0.1192 & $(.047)$ & 0.011 & & & \\
\hline Occas., F/Often, V/Often & -0.2108 & $(.054)$ & 0.000 & & & \\
\hline Uncomfortable eating & & & & -0.0173 & $(.019)$ & 0.362 \\
\hline Hardly ever & -0.0154 & $(.052)$ & 0769 & & & \\
\hline Occas., F/Often, V/Often & -0.0405 & $(.052)$ & 0.442 & & & \\
\hline Felt self-conscious & & & & 0.0281 & $(.026)$ & 0.273 \\
\hline Hardly ever & -0.0830 & $(.050)$ & 0.096 & & & \\
\hline Occas., F/Often, V/Often & 0.0375 & $(.064)$ & 0.559 & & & \\
\hline Felt tense & & & & 0.0289 & $(.027)$ & 0.282 \\
\hline Hardly ever & 0.0893 & $(.053)$ & 0.097 & & & \\
\hline Occas., F/Often, V/Often & 0.0547 & $(.062)$ & 0.377 & & & \\
\hline Diet unsatisfactory & & & & 0.0032 & $(.024)$ & 0.894 \\
\hline Hardly ever & -0.0155 & $(.057)$ & 0.787 & & & \\
\hline Occas., F/Often, V/Often & -0.0595 & $(.060)$ & 0.320 & & & \\
\hline Interrupt meals & & & & -0.0337 & $(.025)$ & 0.188 \\
\hline Hardly ever & -0.0074 & $(.049)$ & 0.880 & & & \\
\hline Occas., F/Often, V/Often & -0.0483 & $(.064)$ & 0.448 & & & \\
\hline Difficulty relaxing & & & & -0.0187 & $(.030)$ & 0.531 \\
\hline Hardly ever & -0.0770 & $(.057)$ & 0.176 & & & \\
\hline Occas., F/Often, V/Often & -0.1074 & $(.066)$ & 0.106 & & & \\
\hline Been embarrassed & & & & 0.0055 & $(.029)$ & 0.850 \\
\hline Hardly ever & -0.0115 & $(.052)$ & 0.825 & & & \\
\hline Occas., F/Often, V/Often & 0.0462 & $(.067)$ & 0.489 & & & \\
\hline Irritable with other people & & & & -0.0186 & $(.030)$ & 0.535 \\
\hline Hardly ever & 0.0598 & $(.054)$ & 0.266 & & & \\
\hline Occas., F/Often, V/Often & -0.0526 & $(.066)$ & 0.429 & & & \\
\hline Difficulty doing usual jobs & & & & -0.0266 & $(.038)$ & 0.481 \\
\hline Hardly ever & -0.0745 & $(.059)$ & 0.207 & & & \\
\hline Occas., F/Often, V/Often & -0.0113 & $(.096)$ & 0.906 & & & \\
\hline Life less satisfying & & & & -0.0550 & $(.026)$ & 0.034 \\
\hline Hardly ever & -0.0502 & $(.057)$ & 0.382 & & & \\
\hline Occas., F/Often, V/Often & -0.0646 & $(.063)$ & 0.307 & & & \\
\hline Unable to function & & & & -0.0177 & $(.037)$ & 0.633 \\
\hline Hardly ever & -0.0387 & $(.080)$ & 0.631 & & & \\
\hline Occas., F/Often, V/Often & -0.0837 & $(.084)$ & 0.319 & & & \\
\hline Sex (male) & 0.0375 & $(.034)$ & 0.271 & 0.0204 & $(.031)$ & 0.518 \\
\hline Age (years) & -0.0005 & $(.001)$ & 0.686 & 0.0002 & $(.001)$ & 0.833 \\
\hline Intercept & 1.1466 & $(.07 I)$ & 0.000 & 1.0822 & $(.060)$ & 0.000 \\
\hline Model: & & & 0.0000 & & & 0.0000 \\
\hline Pseudo R-squared & 0.66 & & & 0.62 & & \\
\hline
\end{tabular}

(I): Reference category: Never

Note: "Occas., F/Often, V/Often" refers to "Occasionally, Fairly often, Very often"

lated with rho ranging between 0.19 and 0.84 . The only correlation above 0.75 occurred between the items 'Felt self-conscious' and 'Been embarrassed'. However dropping one of these items had no effect on the direction of associations and only minimal effect on the pseudo Rsquared value or the significance and magnitude of the regression coefficient, hence the full set of items were retained in the analysis. 
Table 5: Mean relative forecast errors within categories of observed health state values for categorical and item models

\begin{tabular}{|c|c|c|c|c|c|}
\hline \multirow[b]{2}{*}{ Observed health state value category } & \multirow[b]{2}{*}{$\mathbf{n}$} & \multicolumn{2}{|c|}{ Categorical model } & \multicolumn{2}{|c|}{ Item model } \\
\hline & & Mean & {$[95 \% \mathrm{CI}]$} & Mean & {$[95 \% \mathrm{Cl}]$} \\
\hline$<0.70$ & 7 & $28.7 \%$ & {$[8.2-49.1]$} & $24.6 \%$ & {$[10.8-38.4]$} \\
\hline $0.70-<0.80$ & 10 & $13.2 \%$ & {$[6.0-20.3]$} & $17.3 \%$ & {$[8.6-26.0]$} \\
\hline$>0.80$ & 97 & $17.1 \%$ & {$[14.9-19.2]$} & $14.4 \%$ & {$[12.6-16.1]$} \\
\hline All & 114 & $17.4 \%$ & {$[15.2-19.6]$} & $15.2 \%$ & {$[13.5-17.0]$} \\
\hline
\end{tabular}

\section{Discussion}

\section{Response and representativeness}

Response rates to the survey were adequate for both the dentist and patient questionnaires [25]. Comparison of respondents against estimates for private general practice and the Australian population indicated a slightly higher percentage of female patients compared to the population consistent with higher reported visiting rates by females [24], but both place of birth and time since last visit was similar. While dental insurance was higher, the percentage of check-up visits was lower among patients indicating a higher percentage of dental problems for patients compared to the population.

The use of data from a self-selected typical day was used to provide representative estimates. A report has shown that there was no significant difference in service rates in all 10 main areas of service between data collected over a 10-day sampling period compared with estimates based on one typical day nominated from the 10-day sampling period by the responding dentists [22].

\section{Instruments}

Previous analysis of the EuroQol and OHIP-14 instruments found that both the generic and specific measures showed evidence of discriminant validity in detecting associations with visit characteristics and main dental condition being treated among dental patients. There was little difference by type of measure used with simple counts, additive scores and scale scores demonstrating discriminative ability in both bivariate and multivariate analyses [26]. The generic and specific instruments showed a degree of overlap in dimensions, particularly for pain [27]. The partial separation in the domains of both instruments confirms that generic and specific measures can be used in combination to capture different elements of quality of life - with both instruments covering symptom experience of pain but EuroQol tapping daily activities such as self-care and usual activities and OHIP tapping oral health-specific aspects of oral functional limitation and physical disability as well as psychological and social aspects of disability and handicap. There are, however, plausible potential links between the two descriptive systems. For example, mobility could in some persons be influenced by oral health problems, such as severe toothache that results in their seeking bed rest or limiting their movements. It is also worth noting that in this study the EQ-5D was asked in relation to dental problems, hence potential effects of co-morbidity on health state value would not be confounding the relationship between EQ$5 \mathrm{D}$ health states and OHIP-14 items.

As reported for population surveys [10], the distribution of the EuroQol was skewed among dental patients with a minority reporting problems on any one dimension [26]. The effect of skewness is to produce a ceiling effect where most of the responses are clustered at one extreme [28]. This ceiling effect was less marked for the pain/discomfort and anxiety/depression dimensions, but the large numbers of respondents reporting no problems may make the instrument less appropriate for studies of milder conditions [2]. Despite the simplicity of the EuroQol in terms of dimensions and response categories, there is growing evidence of its construct validity [10]. Similarly, the OHIP

Table 6: Mean observed and fitted health state values within categories of observed health state values: categorical model

\begin{tabular}{|c|c|c|c|c|c|}
\hline \multirow[b]{2}{*}{ Observed health state value category } & \multirow[b]{2}{*}{$\mathbf{n}$} & \multicolumn{2}{|c|}{ Observed values } & \multicolumn{2}{|c|}{ Predicted values } \\
\hline & & Mean & {$[95 \% \mathrm{CI}]$} & Mean & {$[95 \% \mathrm{CI}]$} \\
\hline$<0.70$ & 7 & 0.50 & {$[0.38-0.61]$} & 0.61 & {$[0.42-0.82]$} \\
\hline $0.70-<0.80$ & 10 & 0.73 & {$[0.72-0.75]$} & 0.78 & {$[0.68-0.88]$} \\
\hline$>0.80$ & 97 & 0.89 & {$[0.88-0.90]$} & 0.95 & {$[0.92-0.99]$} \\
\hline All & 114 & 0.85 & {$[0.83-0.87]$} & 0.91 & {$[0.88-0.95]$} \\
\hline
\end{tabular}


has also been noted as displaying ceiling effects even among dental patients [29], indicating limitations in both the generic and specific instruments as descriptive measures. Floor effects are just like ceiling effects but they are found at the opposite end of the scale. Floor effects, with high percentages reporting problems, have not been reported to be of the same extent for the EuroQol compared to other generic measures such as SF-6D or HUI3 making it more suitable for generating preference-based index values for use in economic evaluation when the conditions studied are more severe $[2,30]$.

\section{Health state value algorithm}

The present study provides an algorithm that transforms OHIP-14 scores into estimates of health state values. While both the models performed similarly, the lower forecast errors for the continuous model indicate that this may be preferred over the categorical model. This algorithm can then be used in QALY or DALY analyses from databases that contain OHIP-14 scores, but not health state values. While, the preferred method would be to derive health state valuations from a population sample, the mapping algorithm facilitates cost-effectiveness and burden of disease studies through proxy health state values that can be derived from the numerous oral health studies that have collected data using the OHIP instrument.

The proportion of variance explained by the algorithm from a previously reported mapping of a profile measure on an index was between $35 \%-55 \%$ of the variance in HUI3 explained using SF-12 items [3]. In this study the values of pseudo R-squared were higher. However, values of pseudo R-squared are based on likelihood statistics from a model containing the independent variables versus a model containing a constant term only, rather than a comparison of fitted to observed values as obtained from linear regression models (31). Previous mapping studies have cautioned that the use of such mapped utility values would not be appropriate for use at the individual level and instead should be applied to analyses performed at the group level [3]. In the present study, the fitted mean was higher than the observed mean for the group of patients as a whole, and when stratified into different levels of health state value. Hence, an individual's predicted health state value may be an over- or under-estimate of the true health state if it were observed (i.e., directly measured), and as a group, health states would be slightly overestimated. Such variation may be acceptable at a group level where aggregate health state values are of interest. However, some caution should be applied in interpreting findings as health states will tend to be slightly over-estimated (i.e., healthier than if directly measured) and in the case of disability weights for burden of disease studies the over-estimation of health states equates to lower or con- servative estimates of disability weights (i.e., less disability than if directly measured). As participants in this study were dental patients who may have more oral disease than the general population the over-estimation of health states may be exacerbated when applied to general populations. The consistency of the over-estimation of health state values suggests that no systematic variation or bias would result from the application of the algorithm to subgroups with different underlying health states.

\section{Conclusion}

The approach enables health state values to be derived from OHIP-14 scores for populations where utility has not or cannot be measured directly.

\section{Competing interests}

The author(s) declare that they have no competing interests.

\section{Authors' contributions}

DSB and AJS were chief investigators on the grants obtained to fund the study. DSB performed data collection, analysis and drafting of the manuscript. AJS participated in the design and coordination of the study, and completion of the manuscript. All authors read and approved the manuscript.

\section{Acknowledgements}

This research was performed at the Australian Research Centre for Population Oral Health, School of Dentistry, Faculty of Health Sciences at The University of Adelaide with funding from the Australian Dental Research Foundation and University of Adelaide Small Research Grants Scheme. The participation of responding dentists and patients is acknowledged.

\section{References}

I. Allen PF: Assessment of oral health related quality of life. Health Qual Life Outcomes 2003, I:40.

2. Brazier JE, Roberts J: The estimation of a preference-based measure of health from the SF-12. Med Care 2004, 42:85I-9.

3. Sengupta N, Nichol MB, Wu J, Globe D: Mapping the SF- I 2 to the HUI3 and VAS in a managed care population. Med Care 2004, 42:927-37.

4. Brennan DS, Spencer AJ: Disability weights for the burden of oral disease in South Australia. Pop Health Metrics 2004, 2:7.

5. Slade GD, Spencer AJ: Development and evaluation of the oral health impact profile. Community Dent Health I994, I I:3- I I.

6. Locker D: Measuring oral health: a conceptual framework. Community Dent Health 1988, 5:5-13.

7. Slade GD: Derivation and validation of a short-form oral health impact profile. Community Dent Oral Epidemiol 1997, 25:284-90.

8. Brooks R: EuroQol: the current state of play. Health Policy 1996, 37:53-72.

9. Bowling A: Measuring disease A review of disease-specific quality of life measurement scales Second edition. Buckingham: Open University Press; $200 \mathrm{I}$

10. Johnson JA, Coons SJ: Comparison of the EQ-5D and SF-I 2 in an adult US sample. Qual Life Res 1998, 7:155-66.

II. Kind $P$, Dolan P, Gudex C, Williams A: Variations in population health status: results from a United Kingdom national questionnaire survey. BMJ 1998, 3 1 6:736-4I.

12. Stouthard MEA, Essink-Bot M-L, Bonsel G]: Disability weights for diseases. A modified protocol and results for a Western European region. European J Public Health 2000, I 0:24-30. 
13. Anand S, Hanson K: Disability-adjusted life years: a critical review. J of Health Economics 1997, 16:685-702.

14. Murray CJL, Lopez AD, Jamison DT: The global burden of disease in 1990: summary results, sensitivity analysis and future directions. Bull World Health Organ 1994, 72:495-509.

15. Mathers C, Vos T, Stevenson C: The burden of disease and injury in Australia Canberra: Australian Institute of Health and Welfare; 1999.

16. Dillman DA: Mail and telephone surveys. The total design method NY: Wiley; 1978

17. Dolan P: Modeling valuations for EuroQol health states. Med Care 1997, 35: 1095-I108.

18. Austin PC, Escobar M, Kopec JA: The use of the Tobit model for analysing measures of health status. Qual Life Res 2000, 9:901-910.

19. Green WH: Econometric analysis 4th edition. NJ: Prentice-Hall; 2000.

20. Maddala GS: Limited-dependent and qualitative variables in econometrics Cambridge: CUP; 1999.

21. Rothman KJ: Modern epidemiology Boston: Little, Brown and Company; 1986.

22. Brennan DS, Spencer AJ: Dentists' practice activity in Australia: 1983-84 to 1998-99 Canberra: AlHW; 2002.

23. Australian Bureau of Statistics: Australian demographic statistics - March quarter 2002 Canberra: ABS, 3101.0; 2002.

24. Carter KD, Stewart JF, Spencer AJ: National dental telephone interview survey 1999 Adelaide: AlHW DSRU; 2001.

25. Mangione TW: Mail surveys. Improving the quality CA: Sage; 1995.

26. Brennan DS, Spencer AJ: Comparison of a generic and a specific measure of oral health related quality of life. Community Dent Health 2005, 22: I -8.

27. Brennan DS, Spencer AJ: Dimensions of oral health related quality of life measured by the EQ-5D+ and OHIP-I4. Health Qual Life Outcomes 2004, 2:35.

28. Streiner DL, Norman GR: Health measurement scales. A practical guide to their development and use Second edition. Oxford: OUP; 1995

29. Locker D, Matear D, Stephens M, Lawrence H, Payne B: Comparison of the GOHAI and OHIP-I4 as measures of the oral health-related quality of life of the elderly. Community Dent Oral Epidemiol 200I, 29:373-8I.

30. Brazier JE, Harper R, Munro J, Walters SJ, Snaith ML: Generic and condition-specific outcome measures for people with osteoarthritis of the knee. Rheumatology 1999, 38:870-7.

31. Selvin S: Statistical analysis of epidemiologic data Oxford: OUP; 1996.

\section{Pre-publication history}

The pre-publication history for this paper can be accessed here:

http://www.biomedcentral.com/1472-6963/6/96/prepub
Publish with Biomed Central and every scientist can read your work free of charge

"BioMed Central will be the most significant development for disseminating the results of biomedical research in our lifetime. "

Sir Paul Nurse, Cancer Research UK

Your research papers will be:

- available free of charge to the entire biomedical community

- peer reviewed and published immediately upon acceptance

- cited in PubMed and archived on PubMed Central

- yours - you keep the copyright 